\title{
Fading lemonade challenge
}

\section{Hervé This ${ }^{1,2,3}$}

Published online: 13 September 2018

(C) Springer-Verlag GmbH Germany, part of Springer Nature 2018

We would like to invite you to participate in the Analytical Challenge, a series of puzzles to entertain and challenge our readers. This special feature of "Analytical and Bioanalytical Chemistry" has established itself as a truly unique quiz series, with a new scientific puzzle published every three months. Readers can access the complete collection of published problems with their solutions on the ABC homepage at $\mathrm{http}: / / \mathrm{www}$. springer.com/abc. Test your knowledge and tease your wits in diverse areas of analytical and bioanalytical chemistry by viewing this collection.

In the present challenge, lemonade is the topic. And please note that there is a prize to be won (a Springer book of your choice up to a value of $€ 100)$. Please read on...

\section{Meet the fading lemonade challenge}

The following question was received recently via the internet. A correspondent in Italy is preparing lemonade by first boiling lemon peel and mint leaves in water, and then adding lemon juice after the liquid has cooled. The lemonade acquires a pleasant yellow-green color (Fig. 1).

My correspondent wanted to get a slightly bitter and more refreshing taste, so he added some squeezed lemons and let them rest for about $20 \mathrm{~min}$ in the still hot lemonade. The lemonade became much clearer and turned colorless (Fig. 2). A similar effect is observed, he said, when you add lemon juice to black tea.

Hervé This

herve.this@inra.fr

1 INRA, UMR 1145 Ingénierie Procédés Aliments, Group of Molecular Gastronomy, 16 rue Claude Bernard, 75005 Paris, France

2 Ingénierie Procédés Aliments, AgroParisTech, Inra, Université Paris-Saclay, 91300 Massy, France

3 AgroParisTech-Inra International Centre for Molecular Gastronomy, Paris, France
All this is simply cooking and indeed we should not consider culinary questions as cooks, but as chemists. Thus, in order to interpret the above experiment in the spirit of molecular gastronomy, one should note that the juice of lemon (Citrus lemon) is made of water, proteins (1\%), lipids (1\%), sugars $(7 \%)$, organic acids (5\%), with tiny quantities of various pigments, minerals, phenols, and vitamins [1]. Among the various sugars, there are polymers such as pectins, but mainly sucrose, glucose, and fructose. The amount of solid residue obtained from citrus fruits after pressing (in order to extract the juice) accounts for half of the original mass of the whole fruit [2]. The fibrous residue is mainly made of peels (albedo and flavedo) which make nearly one-fourth of the whole fruit mass, seeds, and fruit pulp remaining after juice and essential oil extraction [3].

Mint (Mentha $\times$ piperita L.) [4] is a plant commonly used by the pharmaceutical, cosmetic, and food industries. It has cooling properties because (-)-menthol has receptors on the trigeminal nerve as well as on the olfactory system [5] and it is used for its essential oil [6]. Mint is also said to be a rich

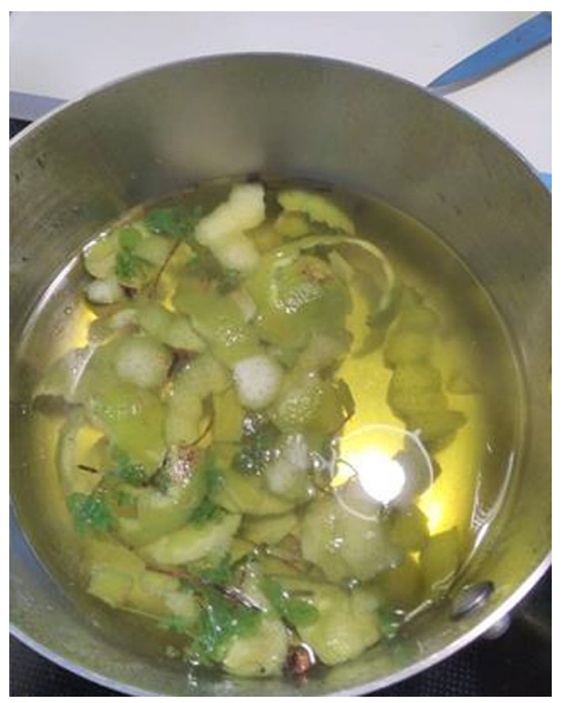

Fig. 1 Lemonade made by adding lemon juice to the aqueous solution obtained by thermal processing of water, sucrose, and the outer skin of lemon Credit: Emil Wörndle (Meran, Italy) 


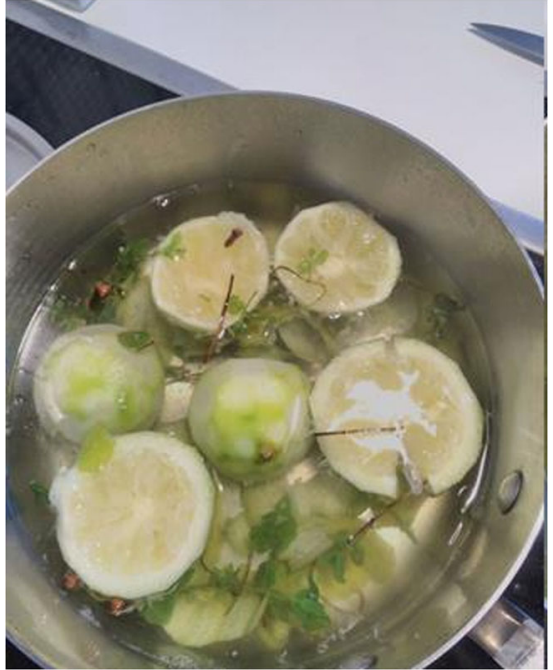

Fig. 2 Lemonade loses its color when the fibrous residue of pressed lemon fruits is added

source of phenolic compounds [4]. The various other compounds present in the mint leaf in decreasing order of magnitude are water, polysaccharides (cellulose, hemicelluloses, pectins), proteins, oligosaccharides and saccharides (including sucrose, glucose, and fructose), amino acids, organic acids (succinic, malic, or tartaric), and smaller quantities of phenolic compounds, chlorophylls, carotenoids, and fragrant compounds making up the essential oil. In the process of making the lemonade, only compounds having a low $\log P$ can be extracted and dissolved in water. As color is considered here, one has to note that chlorophylls and carotenoids are poorly soluble in water $(\log P \approx 15$ for beta-carotene), and only some of their thermal by-products can give color to the aqueous solutions.

\section{The challenge}

Why does lemonade lose its color when squeezed lemons are added to it?

\section{References}

1. Lario Y, Sendra E, Garcia-Perez J, Fuentes C, Sayas-Barbera E, Fernandez-Lopez J, et al. Preparation of high dietary fiber powder from lemon juice by-product. Innov Food Sci Emerg Technol. 2004;5:113-7.

2. Cohn R, Cohn AL. Procesado de frutas. Zaragoza: Acribia; 1997. p. 213-28.

3. Braddock RJ. Handbook of citrus by-products and processing technology. New York: Wiley; 1999. p. 117-33.

4. Sadowska U, Zabinski A, Szumny A, Dziadek K. An effect of peppermint herb (Mentha piperita L.) pressing on physico-chemical parameters of the resulting product. Ind Crop Prod. 2016;94:909-19.

5. Coleman WM, Perfetti TA, Suber RL. Quantitative analysis of menthol isomer distributions in selected samples. J Chromatogr Sci. 1988:36:318-21.

6. European Pharmacopoeia 6.0. Determination of essential oils in herbal drugs. 2008; 2.8.12, 251-252.

We invite our readers to participate in the Analytical Challenge by solving the puzzle above. Please send the correct solution to abcchallenge@springer.com by December 1,2018. Make sure you enter "Fading lemonade challenge" in the subject line of your e-mail. The winner will be notified by e-mail and his/her name will be published on the "Analytical and Bioanalytical Chemistry" homepage at http://www. springer.com/abc and in the journal (volume 411/issue 10) where readers will find the solution and a short explanation

The next Analytical Challenge will be published in 411/1, January 2019. If you have enjoyed solving this Analytical Challenge you are invited to try the previous puzzles on the ABC homepage. 